\title{
sciendo
}

Int. J. of Applied Mechanics and Engineering, 2021, vol.26, No.2, pp.128-142

DOI: 10.2478/ijame-2021-0023

\section{NATURAL FREQUENCIES OF FG PLATES WITH TWO NEW DISTRIBUTION OF POROSITY}

\author{
Slimane MERDACI* \\ Laboratory of Structures and Advanced Materials in Civil Engineering and Public Works \\ University of Djillali Liabès of Sidi Bel Abbes, Faculty of Technology \\ Department of Civil Engineering and Public Works, ALGERIA \\ E-mail: slimanem2016@gmail.com
}

\author{
Adda HADJ MOSTEFA \\ Laboratory of Industrial Engineering and Sustainable Development, Department Civil Engineering \\ Institute of Science \& Technology, University of Rélizane, ALGERIA \\ Osama M.E.S. KHAYAL \\ Nile Valley University, Faculty of Engineering and Technology, Department of Mechanical \\ Engineering, Atbara, SUDAN
}

\begin{abstract}
The functionally graded plates (FGP) with two new porosity distributions are examined in this paper. In this work the plate is modeled using the higher-order shear deformation plate principle. The shear correction variables are neglected. To evaluate the equations of motion, the Hamilton method will be used herein. Therefore, the free vibration analysis of FG plate is developed in this work. For porous smart plates with simply-supported sides, natural frequencies are obtained and verified with the established findings in the literature. The impact of the porosity coefficient on the normal frequencies of the plate for various thickness ratios, geometric ratios, and material properties was investigated in a thorough numerical analysis.
\end{abstract}

Key words: functionally graded plates, natural frequency, even, uneven, porosity.

\section{Introduction}

A heterogeneous composite material that exhibits a continuous variation of mechanical properties from one point to another is a functionally graded material. This substance is created by combining a certain volume ratio with two or more materials. This sort of substance is developed by combining two or more materials with a graded distribution of the volume fractions of the components as discussed by Koizumi et al.[1], such that the FGM is appropriate for different applications, such as thermal barrier coatings for ceramic motors, electrical equipment, energy transformation, biomedical engineering, optics, etc. presented in Refs $[2,12]$.

To examine the vibration of functionally graded surfaces, many experiments have been carried out. A three-dimensional specific solution for free and forced vibrations of dynamically graded rectangular plates which are simply supported was presented by Ferreira et al. [13]. Using a global collocation system, the first and third-order shear deformation plate theories were used to study the free vibrations of dynamically graded plates mentioned in Qian et al. [14]. Latest experiments have used higher-order shear and standard deformable plate theory to examine static deformations and free vibration of dense rectangular and clearly supported plates with dynamically graded elastic plate [15-18]. A three dimensional vibration approach for functionally graded rectangular plates was presented by Matsunaga [19]. Taking into account the effects of

\footnotetext{
* To whom correspondence should be addressed
} 
transverse shear and normal deformations and rotational inertia, natural frequencies and buckling stresses of plates made of dynamically graded materials were analyzed by Rezaei et al. [20]. Askari et al.[21], Merdaci et al. [22], Rezaei et al. [38] and Reddy [39], studied the impact of porosity on the normal frequency of thick porous cellular plates was studied. The researchers investigated the impact of porosity on FGM sandwich plates using the principle of high order shear deformation (Benachour et al. [23]).

A model developed by Belabed et al. [24] for the free vibration of FGM plates with an arbitrary coefficient was based on the same principle developed by Ait Yahia et al. [25]. In other terms, between the volume fraction used to measure Young's modulus and that for density, two separate power indices were taken. Wave propagation in porosity-containing FG plates has recently been studied using various high-order theories and presented by Ebrahimi et al. [7] and Zhao et al. [26]. The analytical solution was suggested in Merdaci et al. [27, 30] and Zhu et al. [31] for the vibration of FGM porosity plates.

In FGM manufacturing, however, micro-porosities or voids may occur inside the products during the sintering phase. This is because of the significant disparity between substance constituents in the temperatures of solidification. It was studied by Wattanasakulpong et al. [32]. Porosities created by a sequential multi-step infiltration process inside FGM specimens was studied by Merdaci [33]. The impact of porosity in the architecture of FGM structures subjected to static was analyzed by Zenkour [34], Merdaci et al. [35], Wattanasakulpong et al. [36], Rezaei et al. [37] studied dynamic loads and reported that they should be taken into account. Consequently, more and more attention has been paid in recent years to studies dedicated to the static and dynamic behavior of FGM material structures.

This current research focuses on the efficiency of free vibration analysis of clearly supported by porous functionally graded plates (FGP) for various porosity distributions based on the HSPT theory of higher-order plates. Even porosity and irregular porosity are thought to be two new forms of porosity distributions, from the thickness direction of the plate. According to the power-law which is adjusted to approximate material characteristics to recognize the effect of porosities, the material characteristics of the FG plate are to be continuously varied throughout the thickness direction. The results of both the bending and shear stresses are superimposed by this theory and a higher-order modification of the axial displacement across the depth of the plate causes that this theory does not include any shear correction element. To deduce the equations of motion from the Hamilton theorem, the four obscure shear deformation theory is used. Hamilton 's theory and the formulation of a Navier-type analytical solution was used to evaluate the P-FGP's motion equations. Compared to other findings produced with the plate hypothesis, the consistency of this hypothesis is confirmed. Several findings are provided to explain the effects of different basic parameters on the natural frequencies of simply supported P-FGP, such as the content index, the fraction of porosity amount, porosity distribution, and length to thickness ratios.

\section{Theoretical formulations}

\subsection{Description of the Model}

Consider, along with the adopted coordinate scheme, a dense rectangular plate FG of length $a$, width $b$ and thickness $h$ made of functionally graded material, as seen in Fig.1.

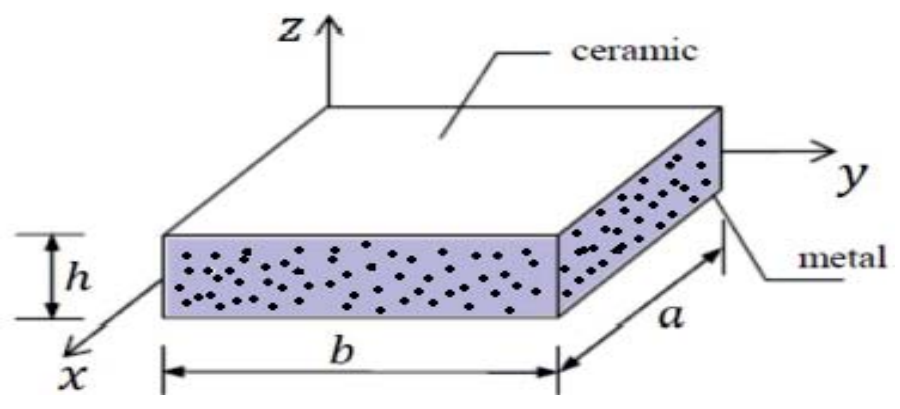

Fig.1. Plate FG dimensional configuration of porosity. 
As can be seen in Fig.2a and Fig.2b, due to the influence of even and uneven porosities in the distribution of material properties, the embedded FG plate becomes an imperfect FG plate. The material properties of the FG plate are believed to be a component of the volume fraction of the constituent components, such as Young's modulus $E$. Due to the progressive volume fraction of the components of the products (ceramic and metal), the properties of the FGM differ constantly, usually in the direction of thickness. To explain these differences in the properties of materials, the function of the P-FGM power rule is widely used. The expression given below describes the volume fraction profile.

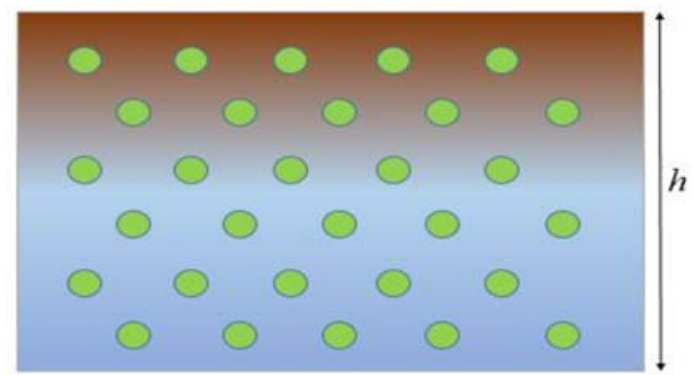

(a) Even porosity

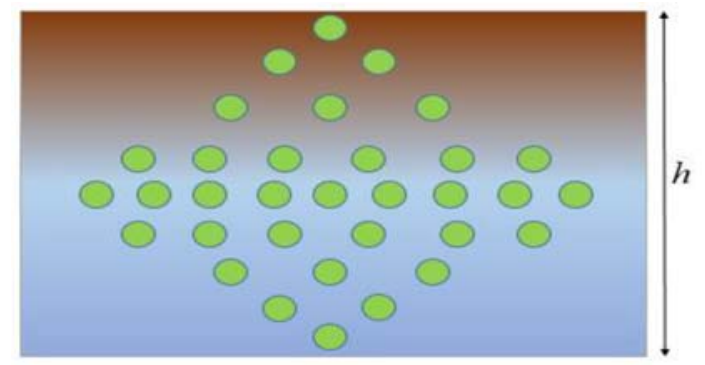

(b) Uneven porosity

Fig.2. Distributions porosity models.

\subsection{Functionally graded materials porosity-dependent}

\subsubsection{Functionally imperfect graded substance of even porosity}

Assume that a combination of metal and ceramic is produced out of the FG layer. It is apparent that with the substrate composition (ceramic and metal) in the direction of thickness, the material properties of the FG plate (i.e., Young's modulus $E$, Poisson's ratio $v$ and mass density $\rho$ ) are constantly altered. Iron is considered to be the bottom side of the rectangular plate and the top surface is composed of ceramic. In addition, the effect of porosities that may occur during processing within the FG plate materials is also included. For a two-phase FG plate with even porosity, the updated mixture rule is as follows:

$$
E(z)=E_{m}\left(1-V-\frac{\xi}{2}\right)+E_{c}\left(V-\frac{\xi}{4}\right) \quad \text { and } \quad V=\left(\frac{1}{2}+\frac{z}{h}\right)^{p}
$$

in which the subscripts $c$ and $m$ reflect, respectively, ceramic and metal, $p$ is also the volume fraction index (power-law index) that determines the characterization of material variance across the thickness of the plate, and the porosity volume fraction is shown by $\xi(0 \leq \xi \leq 1)$. The material properties of the ceramic and the metal, respectively, are $E_{c}$ and $E_{m}$.

In Eq.(2.1) it is necessary to rewrite the material properties of an incomplete FG plate with even porosity (the plan of this model is shown in Fig.2.a) as follows:

$$
\begin{aligned}
& E(z)=E_{m}-\frac{\xi}{4}\left(E_{c}+E_{m}\right)+\left(E_{c}-E_{m}\right)\left(\frac{1}{2}+\frac{z}{h}\right)^{p}, \\
& \rho(z)=\rho_{m}-\frac{\xi}{4}\left(\rho_{c}+\rho_{m}\right)+\left(\rho_{c}-\rho_{m}\right)\left(\frac{1}{2}+\frac{z}{h}\right)^{p} .
\end{aligned}
$$




\subsubsection{Imperfect material of uneven porosity, functionally graded}

For the second distribution model, along the thickness direction (known as uneven distribution) of the FG plate, the porosities may be functionally distributed (the plan of this model is shown in Fig 2(b)) as follows:

$$
\begin{aligned}
& E(z)=E_{m}-\frac{\xi}{4}\left(E_{c}+E_{m}\right)\left(1-\frac{2|z|}{h}\right)+\left(E_{c}-E_{m}\right)\left(\frac{1}{2}+\frac{z}{h}\right)^{p}, \\
& \rho(z)=\rho_{m}-\frac{\xi}{4}\left(\rho_{c}+\rho_{m}\right)\left(1-\frac{2|z|}{h}\right)+\left(\rho_{c}-\rho_{m}\right)\left(\frac{1}{2}+\frac{z}{h}\right)^{p} .
\end{aligned}
$$

The FG plate is composed of a combination of two elements, such as metal and ceramics. It is presumed that the properties of the plate FG content differ continuously throughout the thickness of the plate. The imperfect plate is believed in this analysis to have porosities distributed in thickness due to fault during processing.

\section{Kinematics and strains relations}

The displacement fields can be described based on the assumptions made in the preceding section:

$$
\begin{aligned}
& u(x, y, z, t)=u_{0}(x, y, t)-z \frac{\partial w_{b}}{\partial x}+f(z) \frac{\partial w_{s}}{\partial x}, \\
& v(x, y, z, t)=v_{0}(x, y, t)-z \frac{\partial w_{b}}{\partial y}+f(z) \frac{\partial w_{s}}{\partial y} \\
& w(x, y, z, t)=w_{b}(x, y, t)+w_{s}(x, y, t)
\end{aligned}
$$

where $u_{0}$ and $v_{0}$ mean the displacement functions of the middle surfaces of the plate, in which $t$ represents time. The representative form feature which denotes the distribution of transverse shear stress or strain along the thickness of the plate is also $f(z)$. We have in this study:

$$
f(z)=\sin \left(\frac{\pi}{h} z\right)+\frac{\pi}{2 h} z \quad \text { and } \quad g(z)=f^{\prime}(z)=\frac{d f(z)}{d z}=\frac{\cos \left(\frac{\pi}{h} z\right) \pi}{h}-\frac{\pi}{2 h} .
$$

With the following conclusions, the HSDPT principle takes into consideration transverse shear strain in the formulation.

- The displacements are minimal relative to the thickness of the plate, and the strains concerned are also infinitesimal.

- $\quad$ The transverse displacement $w$ comprises two elements of bending $\left(w_{b}\right)$, and shear $\left(w_{s}\right)$. The bending and shear components are functions of the $x, y$ and $t$ coordinates only, and the $x, y, t$ and $z$ coordinates are functions of the stretching component.

- In-plane displacements $(u$ and $v)$ are classified into contraction, bending and shear sections in the $x$ and $y$ coordinates. The in-plane displacements are seen to be $x, y, t$ and $z$ functions in which the bending components are identical to those given by CPT, and the shear components are aligned with the hyperbolic combinations of shear strains. 
The stress-strain relations are written in the following form for a linear elastic and isotropic plate

$$
\begin{aligned}
& \left\{\begin{array}{l}
\sigma_{x} \\
\sigma_{y} \\
\tau_{x y}
\end{array}\right\}=\left[\begin{array}{ccc}
Q_{11} & Q_{12} & 0 \\
Q_{12} & Q_{22} & 0 \\
0 & 0 & Q_{66}
\end{array}\right]\left\{\begin{array}{l}
\varepsilon_{x} \\
\varepsilon_{y} \\
\gamma_{x y}
\end{array}\right\}, \quad\left\{\begin{array}{l}
\tau_{y z} \\
\tau_{z x}
\end{array}\right\}=\left[\begin{array}{cc}
Q_{44} & 0 \\
0 & Q_{55}
\end{array}\right]\left\{\begin{array}{l}
\gamma_{y z} \\
\gamma_{z x}
\end{array}\right\}, \\
& Q_{11}=Q_{22}=\frac{E(z)}{1-v^{2}}, \quad Q_{12}=\frac{v E(z)}{1-v^{2}}, \quad Q_{44}=Q_{55}=Q_{66}=\frac{E(z)}{2(1+v)}
\end{aligned}
$$

where $\left(\sigma_{x}, \sigma_{y}, \tau_{x y}, \tau_{y z}, \tau_{y x}\right)$ and $\left(\varepsilon_{x}, \varepsilon_{y}, V_{x y}, V_{y z}, V_{z x}\right)$ are the stress and strain components, respectively.

\section{Equations of movement}

To obtain the equations of motion, the Hamilton principle is used herein. In an empirical form, we obtain:

$$
\int_{0}^{T}(\delta U-\delta K) d t=0
$$

where $\delta U$ is the strain energy variation; $\delta K$ is the kinetic energy variation. The variance of the plate's strain energy is determined by

$$
\begin{aligned}
& \delta U=\int_{-h / 2}^{h / 2} \int_{A}\left[\sigma_{x} \delta \varepsilon_{x}+\sigma_{y} \delta \varepsilon_{y}+\tau_{x y} \delta \gamma_{x y}+\tau_{y z} \delta \gamma_{y z}+\tau_{x z} \delta \gamma_{x z}\right] d A d z \\
& \delta U=\int_{A}\left[N_{x} \delta \varepsilon_{x}^{0}+N_{y} \delta \varepsilon_{y}^{0}+N_{x y} \delta \varepsilon_{x y}^{0}+M_{x}^{b} \delta k_{x}^{b}+M_{y}^{b} \delta k_{y}^{b}+M_{x y}^{b} \delta k_{x y}^{b}+\right. \\
& \left.+M_{y}^{s} \delta k_{y}^{s}+M_{y}^{s} \delta k_{y}^{s}+M_{x y}^{s} \delta k_{x y}^{s}+S_{y z}^{s} \delta \gamma_{y z}^{s}+S_{x z}^{s} \delta \gamma_{x z}^{s}\right] d A
\end{aligned}
$$

where " $A$ " is the top surface, and $N, M$ and $S$ are defined by the resulting stress:

$$
\begin{aligned}
& \left\{\begin{array}{ccc}
N_{x}, & N_{y}, & N_{x y} \\
M_{x}^{b}, & M_{y}^{b}, & M_{x y}^{b} \\
M_{x}^{s}, & M_{y}^{s}, & M_{x y}^{s}
\end{array}\right\}=\int_{-h / 2}^{h / 2}\left(\sigma_{x}, \sigma_{y}, \tau_{x y}\right)\left\{\begin{array}{c}
1 \\
z \\
f(z)
\end{array}\right\} d z, \\
& \left(S_{x z}^{s}\right)=\int_{-h / 2}^{h / 2}\left(\tau_{x z}\right) g(z) d z,\left(S_{y z}^{s}\right)=\int_{-h / 2}^{h / 2}\left(\tau_{y z}\right) g(z) d z .
\end{aligned}
$$

It is possible to write the variation of kinetic energy of the plate as

$$
\delta K=\int_{-h / 2}^{h / 2} \int_{A} \rho(z)(\ddot{u} \delta u+\ddot{v} \delta v+\ddot{w} \delta w) d A d z
$$


where the convention of the dot-superscript indicates the distinction with respect to the time variable $t$; and $\left(I_{1}, I_{2}, I_{3}, I_{4}, I_{5}, I_{6}\right)$ are mass inertias defined as

$$
\left(I_{1}, I_{2}, I_{3}, I_{4}, I_{5}, I_{6}\right)=\int_{-h / 2}^{h / 2}\left(1, z, z^{2}, f(z), z f(z), f(z)^{2}\right) \rho(z) d z
$$

The equilibrium equations associated with the modern principle of shear deformation are:

$$
\begin{aligned}
& \delta u: \quad \frac{\partial N_{x}}{\partial x}+\frac{\partial N_{x y}}{\partial y}=\mathrm{I}_{1} \ddot{w}_{0}-\mathrm{I}_{2} \frac{\partial \ddot{w}_{b}}{\partial x}-I_{4} \frac{\partial \ddot{w}_{s}}{\partial x}, \\
& \delta v: \quad \frac{\partial N_{x y}}{\partial x}+\frac{\partial N_{y}}{\partial y}=\mathrm{I}_{1} \ddot{v}_{0}-\mathrm{I}_{2} \frac{\partial \ddot{w}_{b}}{\partial y}-I_{4} \frac{\partial \ddot{w}_{s}}{\partial y}, \\
& \delta w_{b}: \frac{\partial^{2} M_{x}^{b}}{\partial x^{2}}+2 \frac{\partial^{2} M_{x y}^{b}}{\partial x \partial y}+\frac{\partial^{2} M_{y}^{b}}{\partial y^{2}}= \\
& =\mathrm{I}_{1}\left(\ddot{w}_{b}+\ddot{w}_{s}\right)+I_{2}\left(\frac{\partial \ddot{u}}{\partial x}+\frac{\partial \ddot{v}}{\partial y}\right)-I_{3}\left(\frac{\partial^{2} \ddot{w}_{b}}{\partial x^{2}}+\frac{\partial^{2} \ddot{w}_{b}}{\partial y^{2}}\right)-I_{5}\left(\frac{\partial^{2} \ddot{w}_{s}}{\partial x^{2}}+\frac{\partial^{2} \ddot{w}_{s}}{\partial y^{2}}\right) \\
& \delta w_{s}: \frac{\partial^{2} M_{x}^{s}}{\partial x^{2}}+2 \frac{\partial^{2} M_{x y}^{s}}{\partial x \partial y}+\frac{\partial^{2} M_{y}^{s}}{\partial y^{2}}+\frac{\partial S_{x z}^{s}}{\partial x}+\frac{\partial S_{y z}^{s}}{\partial y}= \\
& =\mathrm{I}_{1}\left(\ddot{w}_{b}+\ddot{w}_{s}\right)+I_{4}\left(\frac{\partial \ddot{u}}{\partial x}+\frac{\partial \ddot{v}}{\partial y}\right)-I_{5}\left(\frac{\partial^{2} \ddot{w}_{b}}{\partial x^{2}}+\frac{\partial^{2} \ddot{w}_{b}}{\partial y^{2}}\right)-I_{6}\left(\frac{\partial^{2} \ddot{w}_{s}}{\partial x^{2}}+\frac{\partial^{2} \ddot{w}_{s}}{\partial y^{2}}\right) .
\end{aligned}
$$

The resultants of stress are given as:

$$
\left\{\begin{array}{c}
N \\
M^{b} \\
M^{s}
\end{array}\right\}=\left[\begin{array}{ccc}
A & B & B^{s} \\
A & D & D^{s} \\
B^{s} & D^{s} & H^{s}
\end{array}\right]\left\{\begin{array}{c}
\varepsilon \\
k^{b} \\
k^{s}
\end{array}\right\}, \quad S=A^{s} \gamma
$$

where the plate stiffness is defined by $A_{i j}, B_{i j}$, etc.

$$
\begin{aligned}
& \left\{A_{i j}, B_{i j}, D_{i j}\right\}=\int_{-h / 2}^{h / 2}\left(1, z, z^{2}\right) Q_{i j} d z \quad(i, j=1,2,6), \\
& \left\{B_{i j}^{s}, D_{i j}^{s}, H_{i j}^{s}\right\}=\int_{-h / 2}^{h / 2}\left(f(z), z f(z), f^{2}(z)\right) Q_{i j} d z \quad(i, j=1,2,6), \\
& \left\{A_{i j}^{s}\right\}=\int_{-h / 2}^{h / 2}\left([g(z)]^{2}\right) Q_{i j} d z, \quad(i, j=4,5) .
\end{aligned}
$$




\section{Analytical solutions for FG plates}

In general, rectangular plates are defined according to some of the support used. The exact solution for a simply supported FG plate is discussed in this article. For the side margins, the following boundary conditions are imposed:

$$
\begin{aligned}
& v_{0}=w_{b}=w_{s}=\frac{\partial w_{b}}{\partial y}=\frac{\partial w_{s}}{\partial y}=N_{x}=M_{x}^{b}=M_{x}^{s}=0 \text { and } x=0, a \\
& u_{0}=w_{b}=w_{s}=\frac{\partial w_{b}}{\partial x}=\frac{\partial w_{s}}{\partial x}=0, N_{y}=M_{y}^{b}=M_{y}^{s}=0 \text { and } y=0, b .
\end{aligned}
$$

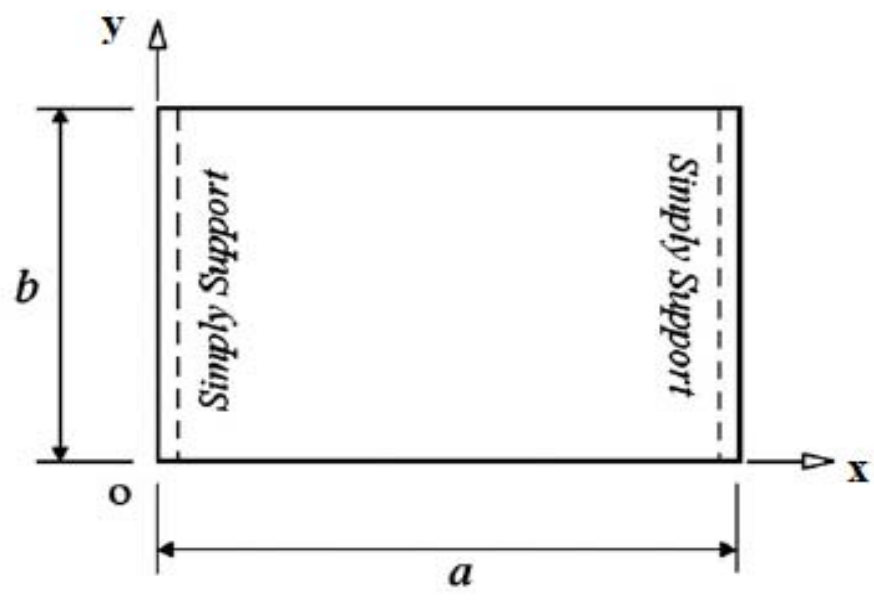

Fig.3. Simply supported FG plate.

We assume the following form of solution for $\left(u, v, w_{b}, w_{s}\right)$ following the Navier solution method that meets the boundary conditions provided in Eqs 5.1.

$$
\left\{\begin{array}{c}
u \\
v \\
w_{b} \\
w_{s}
\end{array}\right\}=\sum_{m=1}^{\infty} \sum_{n=1}^{\infty}\left\{\begin{array}{c}
U_{m n} e^{i \omega t} \cos (\lambda x) \sin (\mu y) \\
V_{m n} e^{i \omega t} \sin (\lambda x) \cos (\mu y) \\
W_{b m n} e^{i \omega t} \sin (\lambda x) \sin (\mu y) \\
W_{s m n} e^{i \omega t} \sin (\lambda x) \sin (\mu y)
\end{array}\right\}
$$

where $U_{m n}, V_{m n}, W_{b m n}$ and $W_{s m n}$ are arbitrary parameters and can be combined into a system of equations as:

$$
\left([K]-\omega^{2}[M]\right)\{\Delta\}=\{0\}
$$

where $[K]$ and $[M]$, are stiffness and mass matrices, respectively, and are represented as: 


$$
\begin{aligned}
& \left(\left[\begin{array}{llll}
a_{11} & a_{12} & a_{13} & a_{14} \\
a_{12} & a_{22} & a_{23} & a_{24} \\
a_{13} & a_{23} & a_{33} & a_{34} \\
a_{14} & a_{24} & a_{34} & a_{44}
\end{array}\right]-\omega^{2}\left[\begin{array}{cccc}
-\mathrm{I}_{1} & 0 & \lambda \mathrm{I}_{2} & \lambda \mathrm{I}_{4} \\
0 & -\mathrm{I}_{1} & \mu \mathrm{I}_{2} & \mu \mathrm{I}_{4} \\
\lambda \mathrm{I}_{2} & \mu \mathrm{I}_{2} & -\left[I_{1}+\mathrm{I}_{3}\left(\lambda^{2}+\mu^{2}\right)\right] & -\mathrm{I}_{5}\left(\lambda^{2}+\mu^{2}\right) \\
\lambda \mathrm{I}_{4} & \mu \mathrm{I}_{4} & -\mathrm{I}_{5}\left(\lambda^{2}+\mu^{2}\right) & -\mathrm{I}_{6}\left(\lambda^{2}+\mu^{2}\right)
\end{array}\right]\right)\left\{\begin{array}{c}
U_{m n} \\
V_{m n} \\
W_{b m n} \\
W_{s m n}
\end{array}\right\}=\left\{\begin{array}{l}
0 \\
0 \\
0 \\
0
\end{array}\right\}, \\
& a_{11}=-\left(A_{11} \lambda^{2}+A_{66} \mu^{2}\right), \quad a_{12}=-\lambda \mu\left(A_{12}+A_{66}\right), \quad a_{31}=a_{13}, \\
& a_{13}=\lambda\left[B_{11} \lambda^{2}+\left(B_{12}+2 B_{66}\right) \mu^{2}\right], \quad a_{14}=\lambda\left[B_{11}^{s} \lambda^{2}+\left(B_{12}^{s}+2 B_{66}^{s}\right) \mu^{2}\right], \\
& a_{21}=a_{12} ; a_{22}=-\left(A_{66} \lambda^{2}+A_{22} \mu^{2}\right), \quad a_{32}=a_{23}, \quad a_{41}=a_{14}, \\
& \left.a_{23}=\mu\left[\left(B_{12}+2 B_{66}\right) \lambda^{2}+B_{22} \mu^{2}\right] ; \quad a_{24}=\mu\left[\left(B_{12}^{s}+2 B_{66}^{s}\right)\right) \lambda^{2}+B_{22}^{s} \mu^{2}\right], \\
& a_{33}=-\left[D_{11} \lambda^{4}+2\left(D_{12}+2 D_{66}\right) \lambda^{2} \mu^{2}+D_{22} \mu^{4}\right], \quad a_{42}=a_{24}, \\
& a_{34}=-\left[D_{11}^{s} \lambda^{4}+2\left(D_{12}^{s}+2 D_{66}^{s}\right) \lambda^{2} \mu^{2}+D_{22}^{s} \mu^{4}\right], \quad a_{43}=a_{34}, \\
& a_{44}=-\left(H_{11}^{s} \lambda^{4}+2\left(H_{12}^{s}+2 H_{66}^{s}\right) \lambda^{2} \mu^{2}+H_{22}^{s} \mu^{4}+A_{55}^{s} \lambda^{2}+A_{44}^{s} \mu^{2}\right)
\end{aligned}
$$

\section{Numerical results and discussion}

Some numerical examples are and addressed here to illustrate the utility and precision of the proposed hypothesis in the static bending and free vibration responses of isotropic homogeneous and FG plates that are simply assisted. Non-dimensional entities were used:

$$
\bar{\beta}=\omega h \sqrt{\rho_{c} / E_{c}}, \quad \tilde{\beta}=\omega h \sqrt{\rho_{m} / E_{m}}, \quad \bar{\omega}=\omega a^{2} / h \sqrt{\rho_{c} / E_{c}} .
$$

The numerical results and a thorough discussion are provided here, based on the equations of the scheme and the solution process in the previous section. An $\mathrm{Al} / \mathrm{Al}_{2} \mathrm{O}_{3}$ functionally graded FGP plate consisting of aluminum (as metal) and alumina (as ceramic) is considered. The aluminum Young modulus and density is $E_{m}=70 G P a$ and $\rho_{m}=2702 \mathrm{~kg} / \mathrm{m}^{3}$, respectively, and that of Alumina $E_{c}=380 \mathrm{GPa}$ and $\rho_{c}=3800 \mathrm{~kg} / \mathrm{m}^{3}$. It is presumed that the Poisson ratio of the plate is stable in the thickness and equal to 0.3 .

Different frequencies of the square plate for clearly supported FGP presented in Tab.1. are used to test the consistency and efficacy of the above technique. Compared to the data available in the literature (Hosseini-Hashemi et al. [17], Matsunaga [19], Askari et al.[21], Benachour et al. [23], Belabed et al.[24] and Rezaei et al. [37]), the frequencies obtained from this analysis are a fine fit for FGP plates. In Tab.2., Rezaei et al. [37, 38] and Askari et al. [22] compared 4 fundamental frequencies of a simply supported rectangular FGP plate with two distinct even and uneven porosity distributions to their counterparts. A strong 
agreement between the observations indicates the consistency of the new method. A further comparison is provided in Tab.3. of the simple natural frequencies of a rectangular $\mathrm{Al}_{/} \mathrm{Al}_{2} \mathrm{O}_{3}$ plate $(\mathrm{b}=2 \mathrm{a})$. The same finding was noted. In other terms, an excellent agreement must be observed [30] between the findings of this model and those of the literature. It should be remembered that the data presented in the three tables are derived from the FG plate for validation purposes. In the above, and after numerous comparisons of the findings, we may conclude that for the analysis of the plates presenting output defects to the current approach is accurate to study porosity.

Table 1. Fundamental frequency comparison $(\bar{\beta})$ for a simply supported FGP and $(a=b=1)$.

\begin{tabular}{|c|c|c|c|c|}
\hline \multirow{2}{*}{$h / a$} & \multirow{2}{*}{ Method } & \multicolumn{3}{|c|}{$p$} \\
\hline & & 0 & 1 & 4 \\
\hline \multirow{6}{*}{0.05} & Benachour et al. [23] & 0,0148 & 0,0113 & 0,0098 \\
\hline & Belabed et al. [24] & 0,0148 & 0,0113 & 0,0098 \\
\hline & Rezaei et al. [37] & 0,0148 & 0,0113 & 0,0098 \\
\hline & Askari et al. [21] & 0,0148 & 0,0113 & 0,0098 \\
\hline & Hosseini-Hashemi et al. [17] & 0.0148 & 0.0113 & 0.0098 \\
\hline & Present & 0,0148 & 0,0113 & 0,0098 \\
\hline \multirow{7}{*}{0.1} & Benachour et al. [23] & 0,0576 & 0,0441 & 0,0380 \\
\hline & Belabed et al. [24] & 0,0578 & 0,0449 & 0,0389 \\
\hline & Rezaei et al. [37] & 0,0578 & 0,0442 & 0,0383 \\
\hline & Askari et al. [21] & 0,0577 & 0,0442 & 0,0380 \\
\hline & Matsunaga [19] & 0.0577 & 0.0443 & 0.0381 \\
\hline & Hosseini-Hashemi et al. [17] & 0.0577 & 0.0442 & 0.0382 \\
\hline & Present & 0,0577 & 0,0442 & 0,0381 \\
\hline \multirow{7}{*}{0.2} & Benachour et al.[23] & 0,2112 & 0,1628 & 0,1375 \\
\hline & Belabed et al. [24] & 0,2121 & 0,1640 & 0,1383 \\
\hline & Rezaei et al.[37] & 0,2127 & 0,1630 & 0,1405 \\
\hline & Askari et al.[21] & 0,2112 & 0,1631 & 0,1377 \\
\hline & Matsunaga [19] & 0.2121 & 0.1640 & 0.1383 \\
\hline & Hosseini-Hashemi et al.[17] & 0.2112 & 0.1631 & 0.1397 \\
\hline & Present & 0,2113 & 0,1631 & 0,1378 \\
\hline
\end{tabular}

The dimensionless natural frequency would decrease as the power index grows for FG plates. The variance curves of the natural frequency of the first mode of different dynamically graded plates perfect and imperfect were shown in figures, for the two porosity distributions, even and uneven as a result of the parameter " $p "$ of the material strength index, for different porosity factor values. It can be shown that the rise in the porosity parameter allows the normal frequency of the first mode to rise. The impact of the thickness ratio $(\mathrm{a} / \mathrm{h})$ on the dimensionless natural frequency parameter of perfect FG plates $(\xi=0)$ and imperfect plates $(\xi=0.1$ and 0.2$)$ for the distribution of porosity is seen in Fig.4. It can be shown that the ratio $(a / h)$ has a major impact on the natural frequency of the FGM plate, which consequently decreases with the rise in this ratio.

The variance of the dimensionless natural frequency as a feature of the geometric ratio (b/a) for the two porosity distributions (even and uneven) is studied in Fig.6. The dimensionless natural frequency is increased by decreasing the said ratio. In addition to the above-mentioned observation, which notes that the rise in the ratio (b/a) decreases the natural frequency without dimensions, it is noted that the ratio (b/a) has 
no effect on the natural frequency variance. This parameter often has virtually no effect on natural frequencies for the ratio $(b / a=3)$ and for the two porosity distributions (even and uneven).

Table 2. Fundamental frequency $(\bar{\beta})$ for a simply supported square FG plate $(p=1$ and $h / a=0.05)$.

\begin{tabular}{|c|c|c|c|c|c|c|}
\hline \multirow[b]{2}{*}{ Distribution } & \multirow{2}{*}{$\xi$} & \multirow{2}{*}{ Method } & \multicolumn{4}{|c|}{$\operatorname{Mode}(\mathrm{m}, \mathrm{n})$} \\
\hline & & & $(1,1)$ & $(1,2)$ & $(2,2)$ & $(1,3)$ \\
\hline \multirow{6}{*}{ (Even) } & \multirow{3}{*}{$\xi=0.1$} & Rezaei et al. $[37,38]$ & 0,0217 & 0,0538 & 0,0851 & 0,1057 \\
\hline & & Askari et al.[21] & 0,0217 & 0,0537 & 0,0850 & 0,1055 \\
\hline & & Present & 0,0213 & 0,0527 & 0,0833 & 0,1034 \\
\hline & \multirow{3}{*}{$\xi=0.2$} & Rezaei et al. $[37,38]$ & 0,0210 & 0,0520 & 0,0824 & 0,1024 \\
\hline & & Askari et al.[21] & 0,0210 & 0,0520 & 0,0823 & 0,1022 \\
\hline & & Present & 0,0203 & 0,0502 & 0,0794 & 0,0985 \\
\hline \multirow{6}{*}{ (Uneven) } & \multirow{3}{*}{$\xi=0.1$} & Rezaei et al. $[37,38]$ & 0,0224 & 0,0553 & 0,0874 & 0,1085 \\
\hline & & Askari et al.[21] & 0,0223 & 0,0552 & 0,0873 & 0,1083 \\
\hline & & Present & 0,0208 & 0,0514 & 0,0814 & 0,1010 \\
\hline & \multirow{3}{*}{$\xi=0.2$} & Rezaei et al. $[37,38]$ & 0,0225 & 0,0555 & 0,0879 & 0,1091 \\
\hline & & Askari et al.[21] & 0,0224 & 0,0554 & 0,0877 & 0,1087 \\
\hline & & Present & 0,0191 & 0,0472 & 0,0747 & 0,0927 \\
\hline
\end{tabular}

Table 3. Natural frequencies $(\bar{\omega})$ for a rectangular plate $\mathrm{Al} / \mathrm{Al}_{2} \mathrm{O}_{3}$.

\begin{tabular}{|c|l|c|c|c|}
\hline \multirow{2}{*}{$a / h$} & \multirow{2}{*}{ Method } & \multicolumn{3}{|c|}{$p=1$} \\
\cline { 3 - 5 } & & $\xi=0$ & $\xi=0.1$ & $\xi=0.2$ \\
\hline \multirow{2}{*}{5} & Mouaici et al. $[30]$ & 2,64760 & 2,59340 & 2,51500 \\
\cline { 3 - 5 } & Present & 2,64753 & 2,54205 & 2,42474 \\
\hline \multirow{2}{*}{10} & Mouaici et al. $[30]$ & 2,79370 & 2,73280 & 2,64520 \\
\cline { 2 - 5 } & Present & 2,79367 & 2,68017 & 2,55388 \\
\hline
\end{tabular}
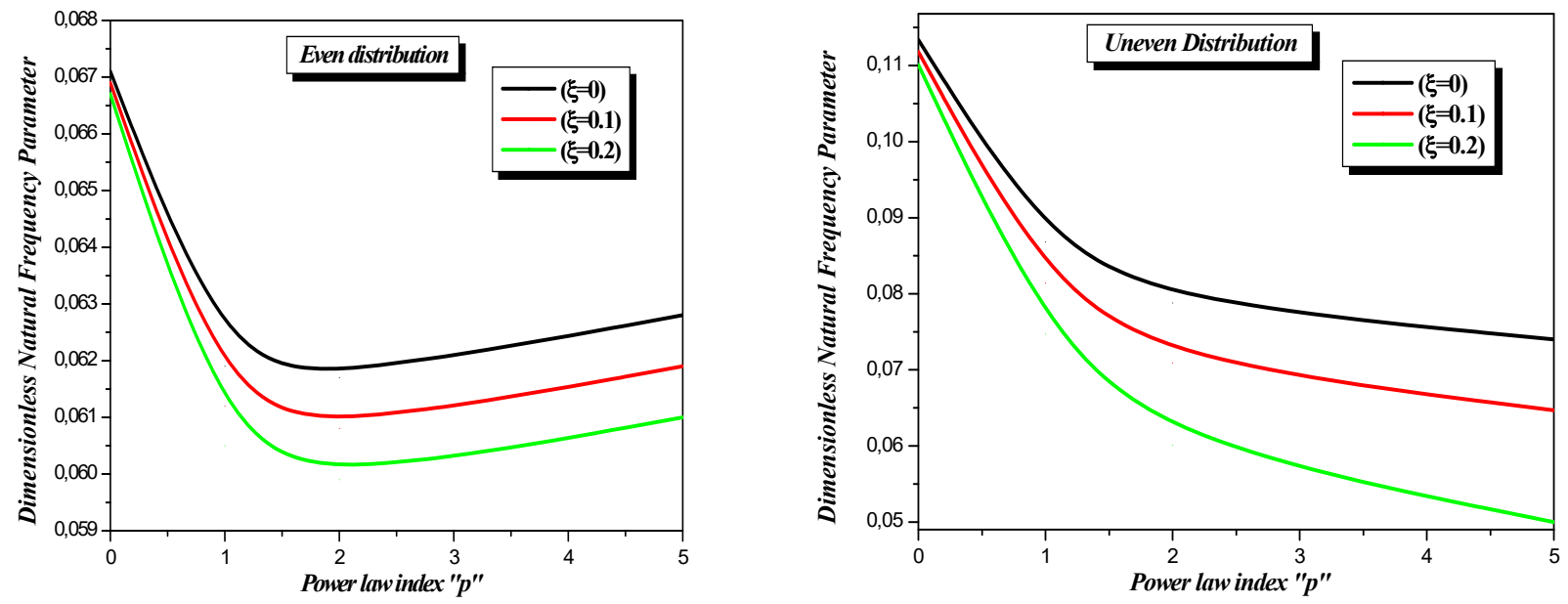

Fig.4. Dimensionless natural frequency parameter $(\bar{\omega})$ of FG plates according to the power index " $p$ " and porosity factor; Mode $1, a=b$ and $a / h=10$. 

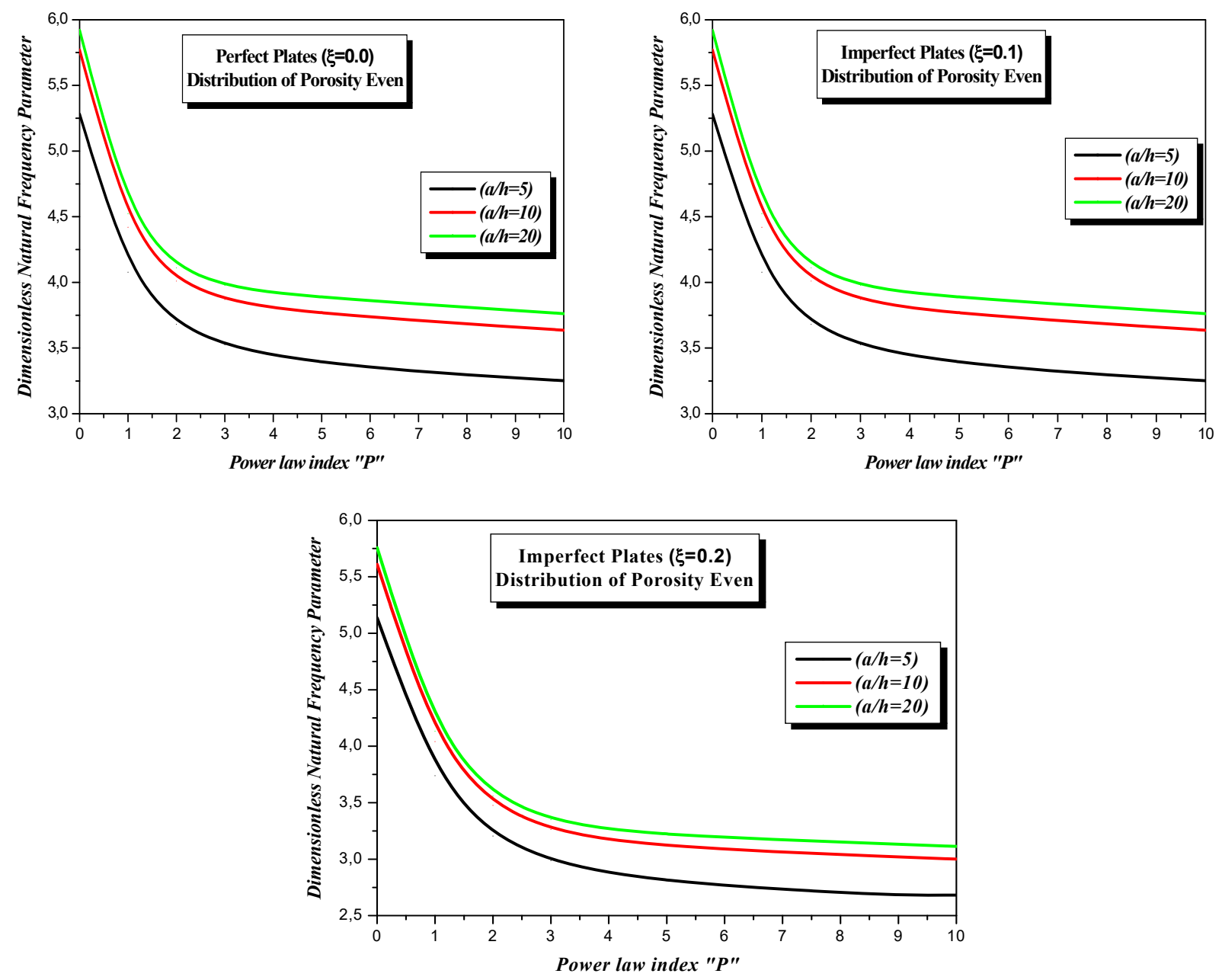

Fig.5. Influence of the thickness ratio $(a / h)$ on the dimensionless natural frequency parameter of the perfect and imperfect FGM plate for even distribution of porosity.
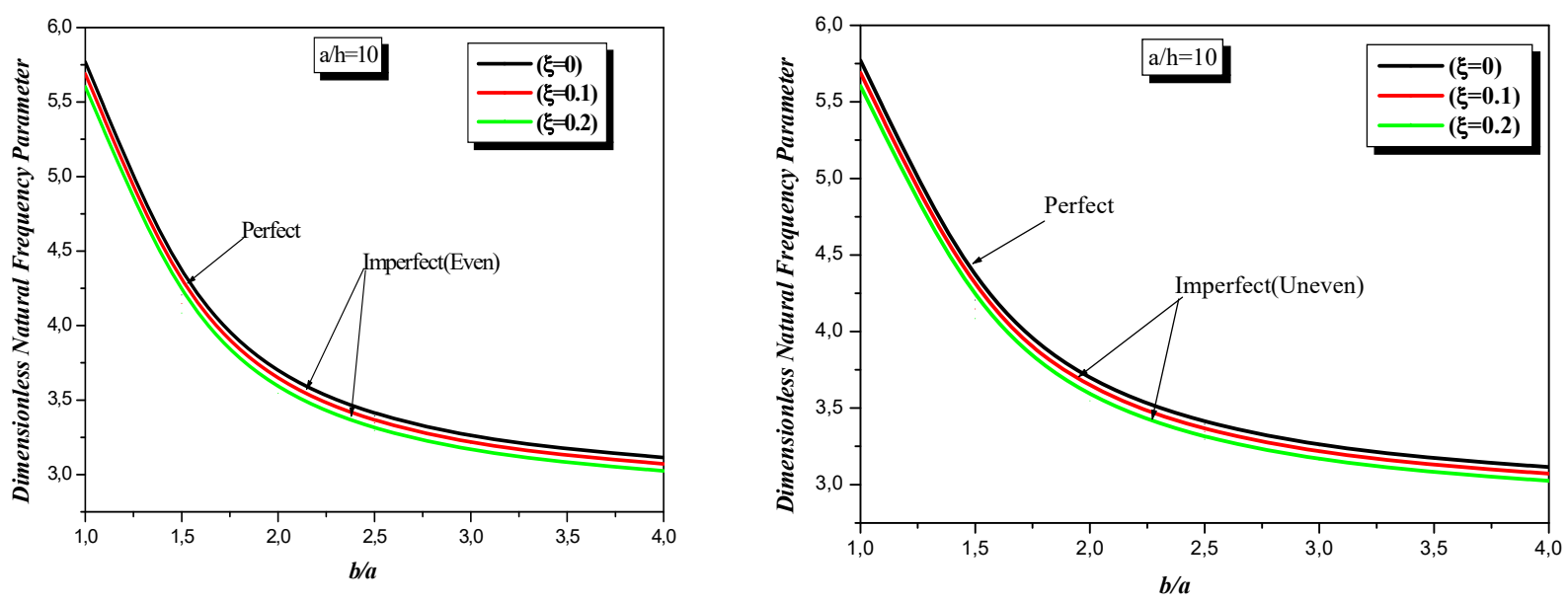

Fig.6. Dimensionless natural frequency as a function of the geometric ratio $(b / a)$ for the two distributions of porosity (even and uneven). 
The variance of the dimensionless natural frequency is expressed in Fig.7. as a function of the thickness ratio $(a / h)$ for the two porosity distributions (even and uneven). For low ratio values $(a / h)$ (i.e. for $a / h<10$ ) (for plates called dense), there is a great difference in the frequency. Exceeding this ratio, whatever the distribution, the dimensionless natural frequencies sustain a more or less steady rate. Furthermore, it should be remembered that the porosity of the distribution (even) provides higher values compared to the other (uneven).
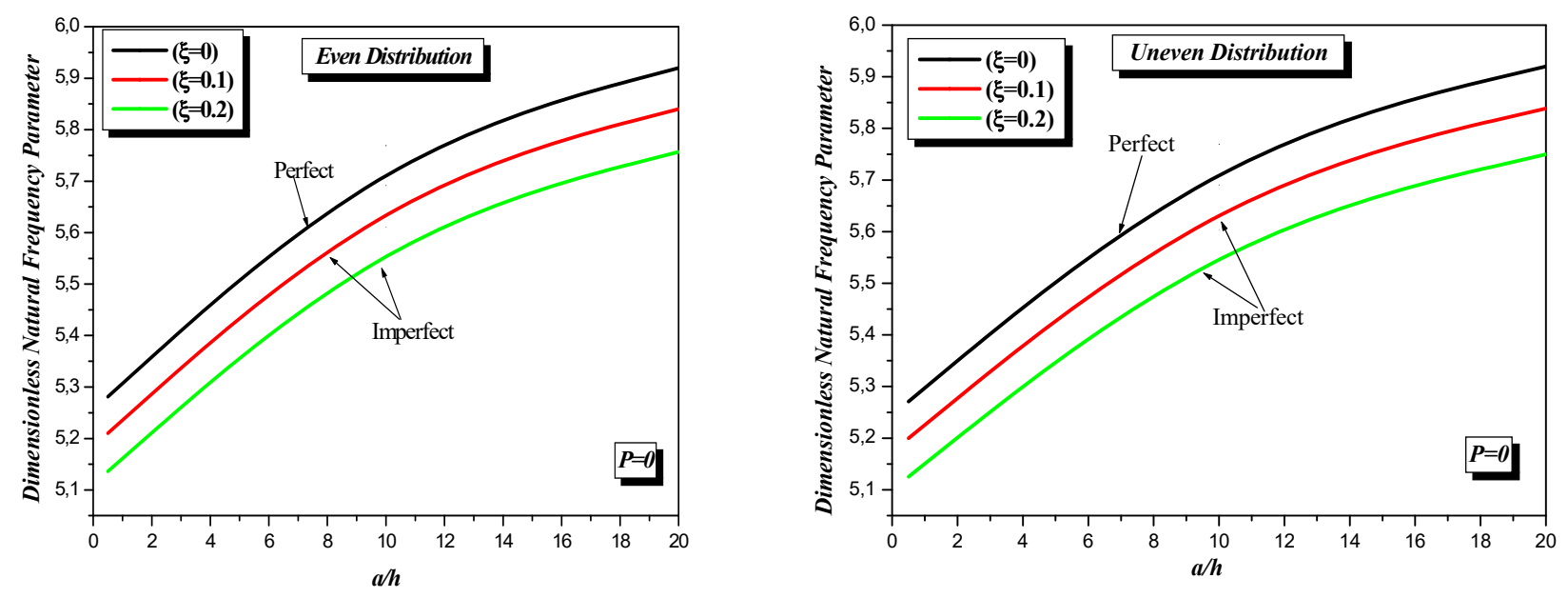

Fig.7. Variation of the dimensionless natural frequency as a function of the thickness ratio $(a / h)$ for the two distributions of porosity (even and uneven).

\section{Conclusions}

In this article, an analytical study of a square and rectangular porous functionally graded FGP plate was mode for free vibration examination. A summary of the most relevant observations is presented here as follows:

- In this investigation, according to the thickness of the layer, the FG plate is believed to have two new porosity distributions, even and uneven.

- To obtain the governing equations of motion, Hamilton 's theory is used.

- This theory's accuracy is verified by contrasting it with other results.

- Some examples are given out to illustrate the impact of the strength index, porosity factor, length to thickness ratios and geometric ratio on the natural frequency of a functionally graded FGP plate.

- It has been shown that the present analytical formulations can reliably model (even and uneven) natural frequencies of FG plates with porosity as compared to other results of Rezaei et al.[37, 38] and Askari et al.[21]

- It is concluded that the influence of volume fraction distributions, slenderness ratio and porosity on the dimensionless natural frequency is important.

\section{Nomenclature}

$$
\begin{aligned}
a & - \text { length of the plate } \\
A & - \text { top surface } \\
A_{i j} & - \text { rigidity terms in membrane of the plate } \\
A_{i j}^{S}, B_{i j}^{S}, D_{i j}^{S}, H_{i j}^{S} & - \text { rigidity terms of the plate in shear } \\
b & - \text { width of the plate }
\end{aligned}
$$




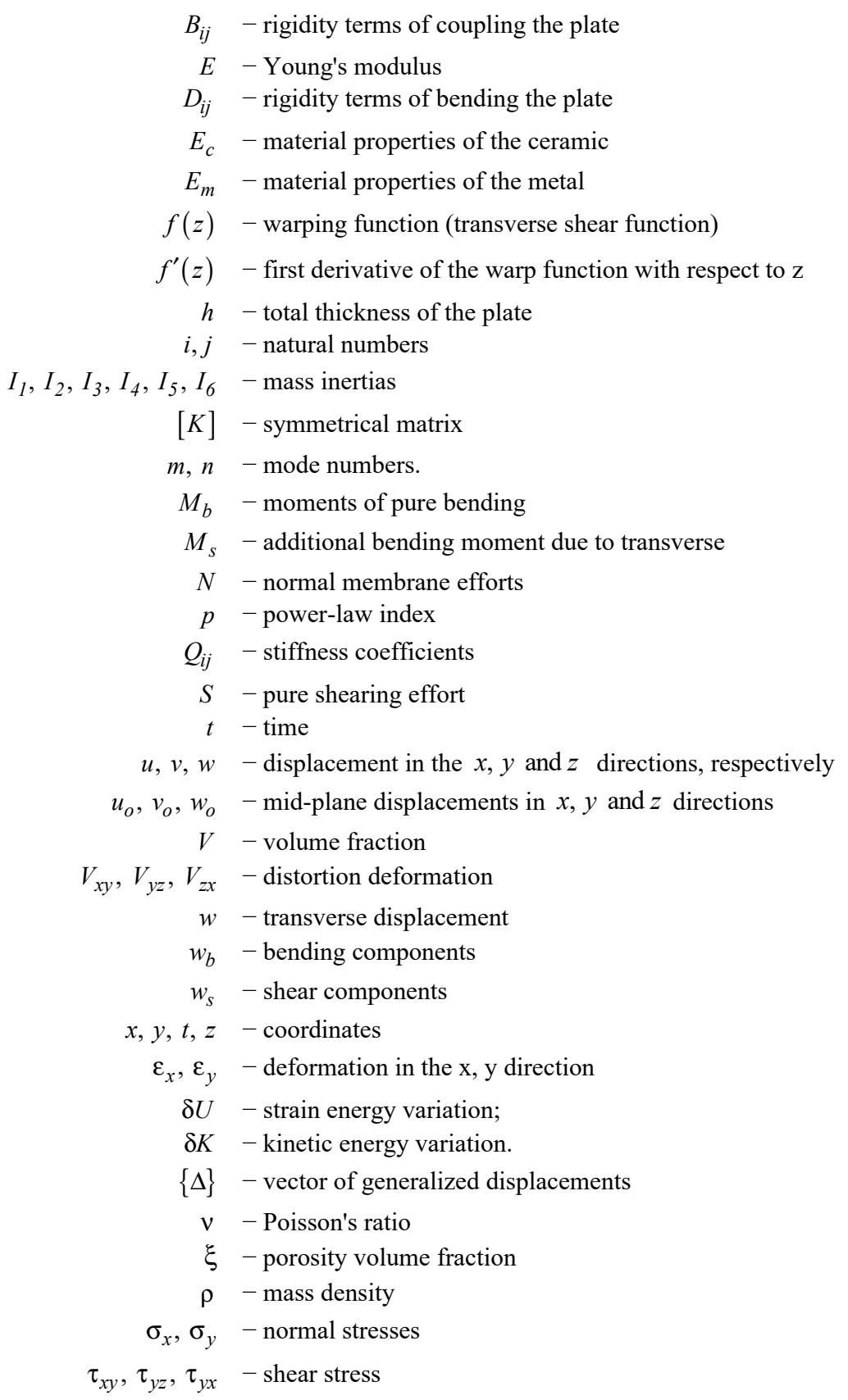

\section{References}

[1] Koizumi M. (1997): FGM activities in Japan.- Compos Part B, vol.28, pp.1-4.

[2] Akbaş Ş. D. (2015): Wave propagation of a functionally graded beam in thermal environments.- Steel and Composite Structures, vol.19, No.6, pp.1421-1447.

[3] Bennai R., Ait Atmane H. and Tounsi A. (2015): A new higher-order shear and normal deformation theory for functionally graded sandwich beams.- Steel and Composite Structures, vol.19, No.3, pp.521-546.

[4] Arefi M. (2015): Elastic solution of a curved beam made of functionally graded materials with different cross sections.- Steel and Composite Structures, vol.18, No.3, pp.659-672. 
[5] Ait Atmane H., Tounsi A., Bernard F. and Mahmoud S.R. (2015): A computational shear displacement model for vibrational analysis of functionally graded beams with porosities.- Steel and Composite Structures, vol.19, No.2, pp.369-384.

[6] Ebrahimi F. and Dashti S. (2015): Free vibration analysis of a rotating non-uniform functionally graded beam.- Steel and Composite Structures, vol.19, No.5, pp.1279-1298.

[7] Ebrahimi F. and Habibi S. (2016): Deflection and vibration analysis of higher-order shear deformable compositionally graded porous plate.- Steel and Composite Structures, vol.20, No.1, pp.205-225.

[8] Darılmaz K. (2015): Vibration analysis of functionally graded material (FGM) grid systems.- Steel and Composite Structures, vol.18, No.2, pp.399-408.

[9] Kar V.R. and Panda S.K. (2016): Nonlinear thermomechanical deformation behaviour of P-FGM shallow spherical shell panel.- Chinese Journal of Aeronautics, vol.29, No.1, pp.173-183.

[10] Hadj Mostefa A., Merdaci S. and Mahmoudi N. (2018): An overview of functionally graded materials «FGM».- Proceedings of the Third International Symposium on Materials and Sustainable Development, ISBN 978-3-319-89706-6, pp.267-278.

[11] Trinh T.H., Nguyen D.K. and Gan B.S., Alexandrov S. (2016): Post-buckling responses of elastoplastic FGM beams on nonlinear elastic foundation.- Structural Engineering and Mechanics, vol.58, No.3, pp.515-532.

[12] Vel S.S. and Batra R.C. (2004): Three-dimensional exact solution for the vibration of functionally graded rectangular plates.- J Sound Vib., vol.272, pp.703-730.

[13] Ferreira A.J.M., Batra R.C., Roque C.M.C., Qian L.F. and Jorge R.M.N. (2006): Natural frequencies of functionally graded plates by a meshless method.- Composite Structures, vol.75, pp.593-600.

[14] Qian L.F., Batra R.C. and Chen L.M. (2004): Static and dynamic deformations of thick functionally graded elastic plates by using higher-order shear and normal deformable plate theory and meshless local Petrov-Galerkin method.- Composites: Part B, vol.35, pp.685-97.

[15] Jha D.K., Kant T. and Singh R.K. (2012): Higher order shear and normal deformation theory for natural frequency of functionally graded rectangular plates.- Nuclear Engineering and Design, vol.250, pp.8-13.

[16] Merazi M., Tounsi A. and Merdaci S. (2020): A refined of trigonometric shear deformation plate theory based on neutral surface position is proposed for static analysis of FGM plate.- Procedia Structural Integrity, vol.26, pp.129-138.

[17] Hosseini-Hashemi Sh., Fadaee M. and Atashipour S.R. (2011): A new exact analytical approach for free vibration of Reissner-Mindlin functionally graded rectangular plates.- International Journal of Mechanical Sciences, vol.53, pp.11-22.

[18] Uymaz B. and Aydogdu M. (2007): Three-dimensional vibration analyses of functionally graded plates under various boundary conditions.- J Reinforced Plast. Compos., vol.26, No.18, pp.1847-1863.

[19] Matsunaga H. (2008): Free vibration and stability of functionally graded plates according to a 2-D higher-order deformation theory.- Composite Structures, vol.82, pp.499-512.

[20] Rezaei A.S. and Saidi A.R. (2016): Application of Carrera Unified Formulation to study the effect of porosity on natural frequencies of thick porous-cellular plates.- Composites Part B: Engineering, vol.91, pp.361-70.

[21] Askari M., Saidi A.R., Rezaei A.S. and Badizi M.A. (2018): Navier-type free vibration analysis of porous smart plates according to reddy's plate theory.- International Conference on Mechanics of Advanced Materials And Equipment, p.13.

[22] Merdaci S. and Hadj Mostefa A. (2020): Influence of porosity on the analysis of sandwich plates FGM using of high order shear-deformation theory.- Frattura ed Integrità Strutturale, vol.51, pp.199-214.

[23] Benachour A., Tahar H. D., Atmane H. A., Tounsi A. and Ahmed M. S. (2011): A four variable refined plate theory for free vibrations of functionally graded plates with arbitrary gradient.- Composites Part B: Engineering, vol.42, No.6, pp.1386-1394. 
[24] Belabed Z., Houari M. S. A., Tounsi A., Mahmoud S. R. and Bég O. A. (2014): An efficient and simple higher order shear and normal deformation theory for functionally graded material (FGM) plates.Composites Part B: Engineering, vol.60, pp.274-283.

[25] Ait Yahia S., Ait Atmane H., Houari M. S. A. and Tounsi A. (2015): Wave propagation in functionally graded plates with porosities using various higher-order shear deformation plate theories.- Struct. Eng. Mech., vol.53, No.6, pp.1143-1165.

[26] Zhao J., Wang Q., Deng X., Choe K., Zhong R. and Shuai C. (2019): Free vibrations of functionally graded porous rectangular plate with uniform elastic boundary conditions.- Composites Part B, vol.168, pp.106-120.

[27] Merdaci S. (2019): Free vibration analysis of composite material plates "Case of a typical functionally graded FG plates ceramic/metal" with porosities.- Nano Hybrids and Composites (NHC), vol.25, pp.69-83.

[28] Merdaci S., Hadj Mostefa A., Merazi M., Belghoul H., Hellal H. and Boutaleb S. (2020): Effects of even pores distribution of functionally graded plate porous rectangular and square.- Procedia Structural Integrity, vol.26, pp.35-45.

[29] Merdaci S. and Hadj Mostefa A. (2020): Free vibration analysis of composite material plates with porosities based on the first-order shear deformation theory.- Journal of Mineral and Material Science (JMMS), vol.1, No.3, pp.1-2.

[30] Mouaici F., Benyoucef S., Ait Atmane H. and Tounsi A. (2016): Effect of porosity on vibrational characteristics of non-homogeneous plates using hyperbolic shear deformation theory.- Wind and Structures, vol.22, No.4, pp.429-454.

[31] Zhu J., Lai Z., Yin Z., Jeon J. and Lee S. (2001): Fabrication of ZrO2-NiCr functionally graded material by powder metallurgy.- Mater. Chem. Phys., vol.68, No.1, pp.130-135.

[32] Wattanasakulpong N., Prusty B.G., Kelly D.W. and Hoffman M. (2012): Free vibration analysis of layered functionally graded beams with experimental validation.- Mater. Des., vol.36, pp.182-190.

[33] Merdaci S. (2018): Analysis of bending of ceramic-metal functionally graded plates with porosities using of high order shear theory.- Advanced Engineering Forum, vol.30, pp.54-70.

[34] Zenkour A.M. (2018): A quasi-3D refined theory for functionally graded single-layered and sandwich plates with porosities.- Composite Structures, vol.201, pp.38-48.

[35] Merdaci S. and Belghoul H. (2019): High order shear theory for static analysis functionally graded plates with porosities.- Comptes Rendus Mecanique, vol.347, No.3, pp.207-217.

[36] Wattanasakulpong N. and Ungbhakorn V. (2014): Linear and nonlinear vibration analysis of elastically restrained ends FGM beams with porosities.- Aerosp. Sci. Technol., vol.32, No.1, pp.111-120.

[37] Rezaei A.S., Saidi A.R., Abrishamdari, M. and Pour Mohammadi M.H. (2017): Natural frequencies of functionally graded plates with porosities via a simple four variable plate theory: An analytical approach.- Thin-Walled Structures, vol.120, pp.366-377.

[38] Rezaei A.S. and Saidi A.R. (2017): On the effect of coupled solid-fluid deformation on natural frequencies of fluid saturated porous plates.- European Journal of Mechanics-A/Solids, vo.63, pp.99-109.

[39] Reddy J.N. (2002): Energy principles and variational methods in applied mechanics.- Wiley, New York.

Received: October 24, 2020

Revised: February 17, 2021 